\title{
Impact of assay temperature on antibody binding characteristics in living cells: A case study
}

\author{
JOÃO CRISPIM ENCARNAÇÃO ${ }^{1,4}$, PAVEL BARTA $^{2}$, TORGNY FORNSTEDT ${ }^{3}$ and KARL ANDERSSON ${ }^{1,4}$ \\ ${ }^{1}$ Ridgeview Instruments AB, Vänge, 74020 Uppsala, Sweden; ${ }^{2}$ Department of Biophysics and \\ Physical Chemistry, Faculty of Pharmacy, Charles University, 50005 Hradec Králové, Czech Republic; \\ ${ }^{3}$ Department of Engineering and Chemical Sciences, Karlstad University, 65188 Karlstad, Sweden; \\ ${ }^{4}$ Department of Immunology, Genetics and Pathology, Uppsala University, 75185 Uppsala, Sweden
}

Received June 8, 2017; Accepted August 24, 2017

DOI: $10.3892 /$ br.2017.982

\begin{abstract}
Kinetic and thermodynamic studies of ligand-receptor interactions are essential for increasing the understanding of receptor activation mechanisms and drug behavior. The characterization of molecular interactions on living cells in real-time goes beyond most current binding assays, and provides valuable information about the dynamics and underlying mechanism of the molecules in a living system. The effect of temperature on interactions in cell-based assays is, however, rarely discussed. In the present study, the effect of temperature on binding of monoclonal antibodies, cetuximab and pertuzumab to specific receptors on living cancer cells was evaluated, and the affinity and kinetics of the interactions were estimated at selected key temperatures. Changes in the behavior of the interactions, particularly in the on- and off-rates were observed, leading to greatly extended time to reach the equilibrium at $21^{\circ} \mathrm{C}$ compared with at $37^{\circ} \mathrm{C}$. However, the observed changes in kinetic characteristics were less than a factor of 10 . It was concluded that it is possible to conduct real-time measurements with living cells at different temperatures, and demonstrated that influences of the ambient temperature on the interaction behavior are likely to be less than one order of magnitude.
\end{abstract}

\section{Introduction}

Over the last 30 years, the development of monoclonal antibodies (mAbs) for treatment of various types of disease, such as cancer or chronic inflammatory disease, has increased markedly (1). Consequently, using mAbs as specific binders to specific targets for potential use in the clinic is continuously being improved and evaluated. The identification and characterization

Correspondence to: Mr. João Crispim Encarnação, Ridgeview Instruments AB, Skillsta 4, Vänge, 74020 Uppsala, Sweden

E-mail: joao@ridgeview.eu

Key words: drug kinetics, thermodynamics, real-time interactions, clinical monoclonal antibodies, growth factor receptors of signaling pathways responsible for the pathogenesis often guides target selection. Furthermore, the identification of various cellular receptors, such as the epidermal growth factor receptor (EGFR), or ligands, such as the vascular EGF (VEGF), improved the understanding of how proteins induce cancer growth via different biological signaling pathways. These findings in turn enabled the construction of proteins capable of interacting and inhibiting their function, such as the development of cetuximab, an mAb against EGFR, and bevacizumab, an $\mathrm{mAb}$ against VEGF (2-6).

The development of novel mAbs and conjugation approaches, for example the conjugation of mAbs with toxins, radionuclides or nanoparticles, aims to strengthen their therapeutic potential against cancer cells $(7,8)$. In such a situation, it is important to understand the behavior of the binding between the antibody and its target to potentially enhance the binding behavior. Investigation of the affinity, and the on- and off-rate provides information regarding the speed at which molecules bind to a receptor, how likely they are to bind, and how stably and strongly they bind. This information explains the differences in cellular responses to facilitate and improve the development of mAb design $(9,10)$.

Various techniques, such as small-angle X-ray scattering, electron microscopy, Förster resonance energy transfer and nuclear magnetic resonance, allow the determination of molecular structure and are fundamental for providing information about the protein-protein interactions. However, kinetic and thermodynamic studies of ligand-receptor interactions are required for understanding the underlying mechanism of receptor activation. For this purpose, techniques, such as surface plasmon resonance enables the measurement of protein-protein interactions in real-time, where the target is evenly exposed in a pure form to the ligand (11). However, a receptor or a protein in a cell has different conformations or is surrounded by different molecules that interfere with the interaction of the ligand that, overall, represents the cellular environment. The measurement of protein interactions on living cells in real-time allows the continuous detection of the quantity of cell-bound ligands, resulting in a binding curve. Binding curves make it possible to estimate the affinity, and the on- and off-rates of the ligand-receptor interaction in a living system $(12,13)$. Spiegelberg et al $(14)$, demonstrated that 
real-time in vitro assays predict the behavior of radio-immunotargeting compounds in in vivo studies. This may lead to a more appropriate selection of potential compounds for in vivo studies, which in turn may reduce the development costs of a drug or imaging compounds.

Another aspect to consider in manual end-point and real-time measurements is that the majority of the ligand-binding studies are performed only at room temperature, which does not allow estimation of thermodynamic coefficients, such as enthalpy and entropy, that are dependent on temperature, and that provide additional important mechanistic information about the biological interaction between the ligand and the receptor. In living material, certain additional challenges occur when binding is evaluated close to $37^{\circ} \mathrm{C}$, as the cell metabolizes and performs processes, including internalization and degradation of the antibody $(15,16)$. However, when the measurements in living materials are conducted at temperatures close to $4^{\circ} \mathrm{C}$, viability and adherence may be an issue.

Unfortunately, the effects of $\mathrm{pH}$ and temperature on binding characteristics are commonly ignored in cell-based assays. Variations in temperature $\left(18-35^{\circ} \mathrm{C}\right)$ or $\mathrm{pH}(5.5-8.5)$ has been shown to affect the measurement of the equilibrium dissociation constant $\left(\mathrm{K}_{\mathrm{D}}\right)$ by a factor of 2 or 10 , respectively (10,17-20), excluding effects due to metabolism.

In the present study, the effect of temperature changes on the binding ability of the mAbs, cetuximab and pertuzumab to their specific receptors in living cancer cells, EGFR and human epidermal growth factor receptor 2 (HER2), respectively were evaluated. Binding was measured in real-time using a LigandTracer ${ }^{\circledR}$ instrument where the affinity and kinetics of the antibody-receptor interactions were derived at three temperatures. The measurement in real-time at different temperatures introduces a unique understanding of the importance of temperature in standard assays, thermodynamics and the true behavior of ligands in living systems.

\section{Materials and methods}

Cell lines. The human SKOV3 ovarian cancer cell line (obtained from the European Collection of Cell Cultures; Public Health England, Salisbury, UK) was cultured in RPMI-1640 (cat. no. F1215; Merck Sharp \& Dohme Ltd., Hoddesdon, UK), and the human A431 squamous carcinoma cell line was cultured in Ham's F10 cell culture medium (cat. no. F0715; Merck Sharp \& Dohme Ltd.). The two types of cell culture media were supplemented with $10 \%$ fetal bovine serum (cat. no. F6765; Sigma-Aldrich; Merck KGaA, Darmstadt, Germany), 2 mM L-glutamine (cat. no. K0283; Merck Sharp \& Dohme Ltd.), $100 \mathrm{IU}$ penicillin and $100 \mu \mathrm{g} / \mathrm{ml}$ streptomycin (cat. no. A2213; Merck Sharp \& Dohme Ltd.). LigandTracer studies were performed as described by Björkelund et al (21). In brief, cells were seeded on a local area of a $10 \mathrm{~cm}$ petri dish (Nunclon $^{\mathrm{TM}}$; cat. no. 150350; Thermo Fisher Scientific, Inc., Waltham, MA, USA) and placed in an incubator at $37^{\circ} \mathrm{C}$, and used within 3 days after seeding.

Antibody labeling. Pertuzumab (purified from Omnitarg ${ }^{\mathrm{TM}}$; Genentech, Inc., South San Francisco, CA, USA) was labeled with Texas Red ${ }^{\circledR}$ label (Invitrogen; Thermo Fisher Scientific, Inc.), the targets of which are primary amines, i.e., lysines. For this purpose, the clinical mAb was labeled as described by Bondza et al (22). Additionally, cetuximab (purified from Erbitux ${ }^{\circledR}$; Merck KGaA) was labeled with fluorescein isothiocyanate (FITC; cat. no. F3651; Sigma-Aldrich; Merck KGaA) as described by Stenberg et al (13). The labeled proteins were purified through a NAP-5 column (GE Healthcare Life Sciences, Little Chalfont, UK) for the removal of unbound fluorophore.

Analyzing antibody-receptor interactions in real-time at different temperatures. The cetuximab-EGFR and pertuzumab-human epidermal growth factor receptor 2 (HER2) interactions in living cells were measured in real time using LigandTracer Green (Ridgeview Instruments $\mathrm{AB}$, Vänge, Sweden) at $8,15,21$ and $37^{\circ} \mathrm{C}$. The LigandTracer technology measures the signal in a specific area of a Petri dish, the interaction between a target (in this case HER2 and EGFR expressed on SKOV3 and A431 cells, respectively) and a specific ligand, which is either radiolabeled or labeled with fluorescence (in this case cetuximab and pertuzumab were labeled with the fluorescent dye, FITC and Texas Red ${ }^{\circledR}$, respectively). This technology has been used to measure real time interactions on living cells in various previous studies (23-25). All measurements in the present study were performed using two detectors: The yellow (590 nm) to red $(632 \mathrm{~nm})$ detector (for the Texas Red label) and the blue $(488 \mathrm{~nm})$ to green $(535 \mathrm{~nm})$ detector (for the FITC label).

For the temperature measurements, the LigandTracer instrument was placed either in an incubator $\left(37^{\circ} \mathrm{C}\right)$ for cell culture, at room temperature $\left(\sim 21^{\circ} \mathrm{C}\right)$, in a Styrofoam box equipped with a Peltier cooling element tuned to maintaining the temperature at $\sim 15^{\circ} \mathrm{C}$ for $24 \mathrm{~h}$ (thermobox), and in a cold room maintained at $\sim 8^{\circ} \mathrm{C}$. The instrument was placed in each condition for at least $2 \mathrm{~h}$ before starting the assay to allow the temperature equilibrate. The assay temperature was continuously monitored in the instrument during measurements.

The interaction between Texas Red-pertuzumab and HER2 was characterized in LigandTracer Green, where Texas Red-pertuzumab was added to a Petri dish with seeded SKOV3 cells containing RPMI cell culture medium $(3 \mathrm{ml})$. The cells were incubated with a first concentration of Texas Red-pertuzumab ( $4 \mathrm{nM}$ ) for $1.5 \mathrm{~h}$, followed by the second addition of Texas Red-pertuzumab (12 nM) for a further $3 \mathrm{~h}$ incubation. Subsequent to the last addition, RPMI medium was replaced with fresh medium and measurements were performed to evaluate the dissociation process. This protocol was performed at all incubation temperatures $(8,15,21$ and $\left.37^{\circ} \mathrm{C}\right)$.

An alternative experimental setup was also tested, where the association and dissociation were detected separately. In the case of the association phase, an initial measurement was obtained where the cells were incubated with $4 \mathrm{nM}$ Texas Red-pertuzumab for the first $3 \mathrm{~h}$ of the association phase, followed by $12 \mathrm{nM}$ Texas Red-pertuzumab for the second $3 \mathrm{~h}$ association phase. The dissociation process was evaluated in a separate measurement by the saturation of the cell receptor system where first, the detection of rapid HER2 saturation with Texas Red-pertuzumab (100 nM) was performed during $30 \mathrm{~min}$ of measurement, followed by the replacement of the 
Table I. Summary of the kinetic constants $\left(\mathrm{k}_{\mathrm{a}}\right.$ and $\left.\mathrm{k}_{\mathrm{d}}\right)$ and affinities $\left(\mathrm{K}_{\mathrm{D}}\right)$ presented with SE obtained at $15^{\circ} \mathrm{C}(\mathrm{n}=2), 37^{\circ} \mathrm{C}(\mathrm{n}=2)$ or $21^{\circ} \mathrm{C}(\mathrm{n}=3)$ for the interaction Texas Red-pertuzumab with human epidermal growth factor receptor 2 in SKOV3 cells.

\begin{tabular}{lccc}
\hline Temperature, ${ }^{\circ} \mathrm{C}^{\mathrm{a}}$ & $\mathrm{k}_{\mathrm{a}}\left(\mathrm{M}^{-1} \mathrm{~s}^{-1}\right) \pm \mathrm{SE}$ & $\mathrm{k}_{\mathrm{d}}\left(\mathrm{s}^{-1}\right) \pm \mathrm{SE}$ & $\mathrm{K}_{\mathrm{D}}(\mathrm{M}) \pm \mathrm{SE}$ \\
\hline $15(14.8-16.2)^{\mathrm{b}}$ & $2.7 \times 10^{4} \pm 0.07 \times 10^{4}$ & - & - \\
$21(20.5-21.6)$ & $2.42 \times 10^{4} \pm 0.21 \times 10^{4}$ & $\sim 10^{-6}$ & $\sim 10^{-10}$ \\
$37(36.5-37.7)$ & $1.35 \times 10^{5} \pm 0.11 \times 10^{5}$ & $4.63 \times 10^{5} \pm 0.92 \times 10^{-5}$ & $3.43 \times 10^{-10} \pm 0.97 \times 10^{-10}$ \\
\hline
\end{tabular}

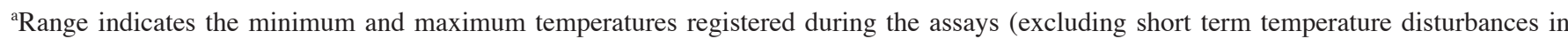
conjunction with accessing the instrument to change concentrations). ${ }^{b} \mathrm{~K}_{\mathrm{D}}$ is not displayed as kd was difficult to determine. SE, standard error; $\mathrm{k}_{\mathrm{a}}$, association rate constant; $\mathrm{k}_{\mathrm{d}}$, dissociation rate constant; $\mathrm{K}_{\mathrm{D}}$, equilibrium dissociation constant.
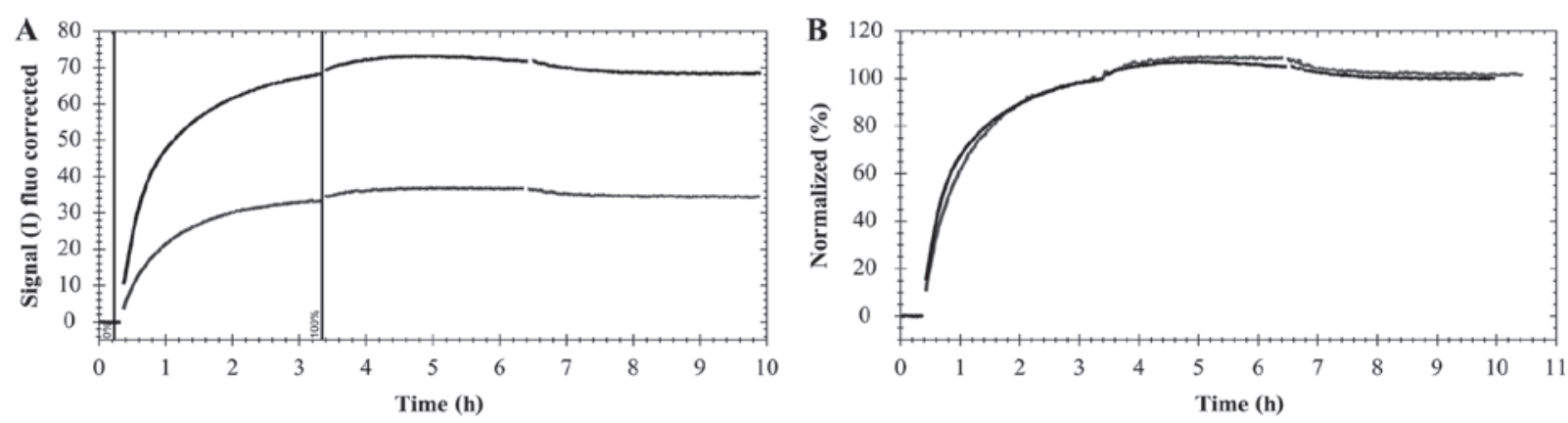

Figure 1. An example of normalization of real-time interaction curves from the association process for the first antibody concentration produced by TraceDrawer. (A) Level of the signal in the two binding curves prior to normalization. (B) The two curves were normalized following exposure to the initial antibody concentration.

incubation medium with fresh medium to measure the dissociation process.

The interaction between FITC-cetuximab and EGFR was characterized by adding a specific volume of FITC-cetuximab to the final concentration of $9 \mathrm{nM}$ in A431 cells in a Petri dish, and containing the incubation medium $(3 \mathrm{ml})$. This approach was used for all investigated temperature points. For this purpose, the cells were incubated with FITC-cetuximab $(3 \mathrm{nM})$ for $3 \mathrm{~h}$ initially. Subsequently, the addition of the next portion of FITC-cetuximab (to a total of $9 \mathrm{nM}$ ) was added followed by $3 \mathrm{~h}$ incubation at the different temperatures. When the association phase was complete, the incubation medium containing the labeled $\mathrm{mAb}$ was replaced with fresh medium $(3 \mathrm{ml})$, allowing detection of the dissociation process in the same measurement.

Statistical analysis. The shapes of the real-time binding curves produced by LigandTracer Green were compared using the evaluation software, TraceDrawer 1.7.1 (Ridgeview Instruments $\mathrm{AB}$ ). The curves were normalized to compensate for any differences in signal magnitude caused by, for example, variations in cell number and labeling efficiency. Normalization enabled a clear visual presentation of differences in binding kinetics, observed as variations in curvature. The signal at the end of the first incubation phase was set to $100 \%$ and the curves were scaled according to Fig. 1.

Data fitting was conducted essentially, as previously described by Bondza et al (22) for the pertuzumab-HER2 interaction and by Barta et al (26) for cetuximab-EGFR, to obtain information regarding the equilibrium dissociation constant, $\mathrm{K}_{\mathrm{D}}$ (corresponding to the affinity), the association rate constant, $\mathrm{k}_{\mathrm{a}}$ and the dissociation rate constant, $\mathrm{k}_{\mathrm{d}}$.

\section{Results}

Analysis of pertuzumab-HER2 interaction in SKOV3 cells. Attempts to evaluate the interactions (for SKOV3 and A431) at $\sim 8^{\circ} \mathrm{C}$ failed approximately every second assay due to cells detaching from the cell dish shortly after initiating measurement. Characterization of the interactions between Texas Red-pertuzumab and HER2 at different temperatures were performed by two-step incubation with two different $\mathrm{mAb}$ concentrations (4 and $12 \mathrm{nM}$; Fig. 2).

The interaction of Texas Red-pertuzumab with HER2 reached equilibrium at different times for different temperatures (Fig. 2). At $37^{\circ} \mathrm{C}$, when the Texas Red-pertuzumab was added to a final concentration of $4 \mathrm{nM}$, the interaction required $\sim 3 \mathrm{~h}$ to approach equilibrium (Fig. 2C). However, the interaction was significantly slower at 15 and $21^{\circ} \mathrm{C}$, requiring $\sim 5 \mathrm{~h}$ for the concentration of $12 \mathrm{nM}$ to approach equilibrium (Fig. 2A and B). Following $6 \mathrm{~h}$ of incubation with Texas Red-pertuzumab at $37^{\circ} \mathrm{C}$, the signal began to drop marginally, indicating that Texas Red-pertuzumab began to be internalized and degraded in the cells (Fig. 2C; time $>6$ h). After 7-8 h, the incubation solution was replaced with fresh cell culture medium, allowing detection of the dissociation process.

Table I summarizes the kinetic constants and affinities presented with standard error (SE) obtained at $15^{\circ} \mathrm{C}(\mathrm{n}=2)$, $37^{\circ} \mathrm{C}(\mathrm{n}=2)$ or $21^{\circ} \mathrm{C}(\mathrm{n}=3)$ for the Texas Red-pertuzumab interaction with HER2 in the SKOV3 cells. As $k_{d}$ was difficult to 
Table II. Summary of the kinetic constants $\left(\mathrm{k}_{\mathrm{a}}\right.$ and $\left.\mathrm{k}_{\mathrm{d}}\right)$ and affinities $\left(\mathrm{K}_{\mathrm{D}}\right)$, presented with SE for the interaction fluorescein isothiocyanate-cetuximab with epidermal growth factor receptor in A431 cells at different temperatures $(n=2)$.

\begin{tabular}{lccr}
\hline Temperature, ${ }^{\circ} \mathrm{C}^{\mathrm{a}}$ & $\mathrm{k}_{\mathrm{a}}\left(\mathrm{M}^{-1} \mathrm{~S}^{-1}\right) \pm \mathrm{SE}$ & $\mathrm{k}_{\mathrm{d}}\left(\mathrm{s}^{-1}\right) \pm \mathrm{SE}$ & $\mathrm{K}_{\mathrm{D}}(\mathrm{M}) \pm \mathrm{SE}$ \\
\hline $15(14.8-16.4)$ & $1.37 \times 10^{5} \pm 0.01 \times 10^{5}$ & $7.01 \times 10^{-6} \pm 0.08 \times 10^{-6}$ & $5.12 \times 10^{-11} \pm 1.16 \times 10^{-11}$ \\
$21(20.2-21.3)$ & $1.16 \times 10^{5} \pm 0.03 \times 10^{5}$ & $9.79 \times 10^{-6} \pm 0.05 \times 10^{-6}$ & $8.44 \times 10^{-11} \pm 0.27 \times 10^{-11}$ \\
$37(36.9-37.8)$ & $3.33 \times 10^{5} \pm 0.09 \times 10^{5}$ & $7.9 \times 10^{-6} \pm 2.70 \times 10^{-6}$ & $2.37 \times 10^{-11} \pm 0.87 \times 10^{-11}$ \\
\hline
\end{tabular}

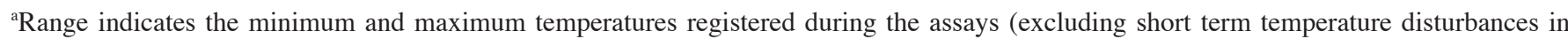
conjunction with accessing the instrument to change concentrations). SE, standard error; $\mathrm{k}_{\mathrm{a}}$, association rate constant; $\mathrm{k}_{\mathrm{d}}$, dissociation rate constant; $\mathrm{K}_{\mathrm{D}}$, equilibrium dissociation constant.
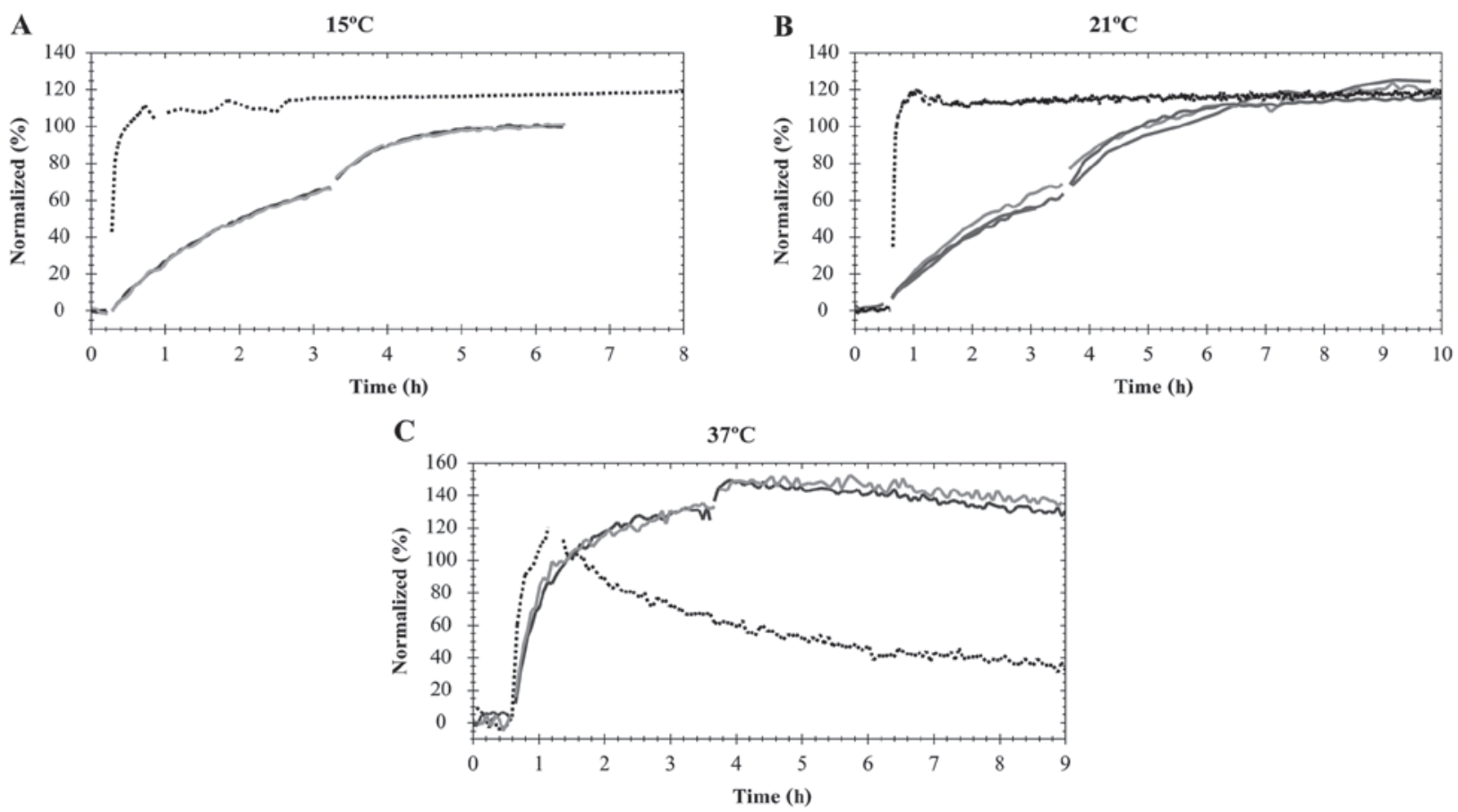

Figure 2. SKOV3 cells were incubated with final concentrations of Texas Red-pertuzumab (4 and 12 nM added step-wise; incubation time, 3 h per concentration). Measurements conducted at (A) $15^{\circ} \mathrm{C}(\mathrm{n}=2),(\mathrm{B}) 21^{\circ} \mathrm{C}(\mathrm{n}=3)$ and $(\mathrm{C}) 37^{\circ} \mathrm{C}(\mathrm{n}=2)$. The black dotted curve depicts evaluation of the dissociation process at all temperatures [receptor saturation for $30 \mathrm{~min}$ with Texas Red-pertuzumab $(100 \mathrm{nM})$ followed by the dissociation phase over time during the wash-out: $0 \mathrm{nM}$ ]. The use of different shades of gray for the association curves denotes results from individual replicates.

determine, $\mathrm{K}_{\mathrm{D}}$ is not displayed $\left(15^{\circ} \mathrm{C}\right)$. The temperature range demonstrates the minimum and maximum temperatures registered during the assays (excluding short term temperature disturbances in conjunction with accessing the instrument to change concentrations).

As observed in Fig. 2, it was not possible to investigate association and dissociation processes in one run. Initial attempts to evaluate the association and dissociation with just one experiment failed to estimate the $\mathrm{k}_{\mathrm{d}}$ value, irrespective of temperature (data not shown). Therefore, a set of separate experiments was conducted to investigate the dissociation processes alone. The two curves were evaluated simultaneously via global fitting to estimate the association and dissociation rate constants at the different temperatures, as represented in Table I. Going from 21 to $37^{\circ} \mathrm{C}$ resulted in a five-fold increase of the association rate constant of the pertuzumab-HER2 interaction. By contrast, no increase in $\mathrm{k}_{\mathrm{a}}$ was observed when increasing from 15 to $21^{\circ} \mathrm{C}$. In the current study, the $\mathrm{k}_{\mathrm{d}}$ for the pertuzumab-HER2 interaction at $15^{\circ} \mathrm{C}$ was smaller than the detection limit for LigandTracer (set at $\sim 1 \times 10^{-6} \mathrm{~s}^{-1}$ for the assay conditions in the present study). Additionally, at $21^{\circ} \mathrm{C}$, the $\mathrm{k}_{\mathrm{d}}$ could not be calculated with precision, but it was possible to estimate that it was $<3 \times 10^{-6} \mathrm{~s}^{-1}$ and $\sim 10^{-6}$. Hence, the affinity value could not be accurately derived, but is estimated to be $10^{-10} \mathrm{M}$.

Analysis of cetuximab-EGFR interaction in A431 cells. Furthermore, it was possible to observe that the interaction of FITC-cetuximab with EGFR in A431 cells was similar to that of pertuzumab-HER2. Namely, temperature influences the time that the interaction requires to approach equilibrium (Fig. 3). When A431 cells were exposed to the first concentration of FITC-cetuximab (3 $\mathrm{nM}$ ), equilibrium was approached within $1 \mathrm{~h}$ at $37^{\circ} \mathrm{C}$ (Fig. 3C). This was not observed at 21 or $15^{\circ} \mathrm{C}$, 

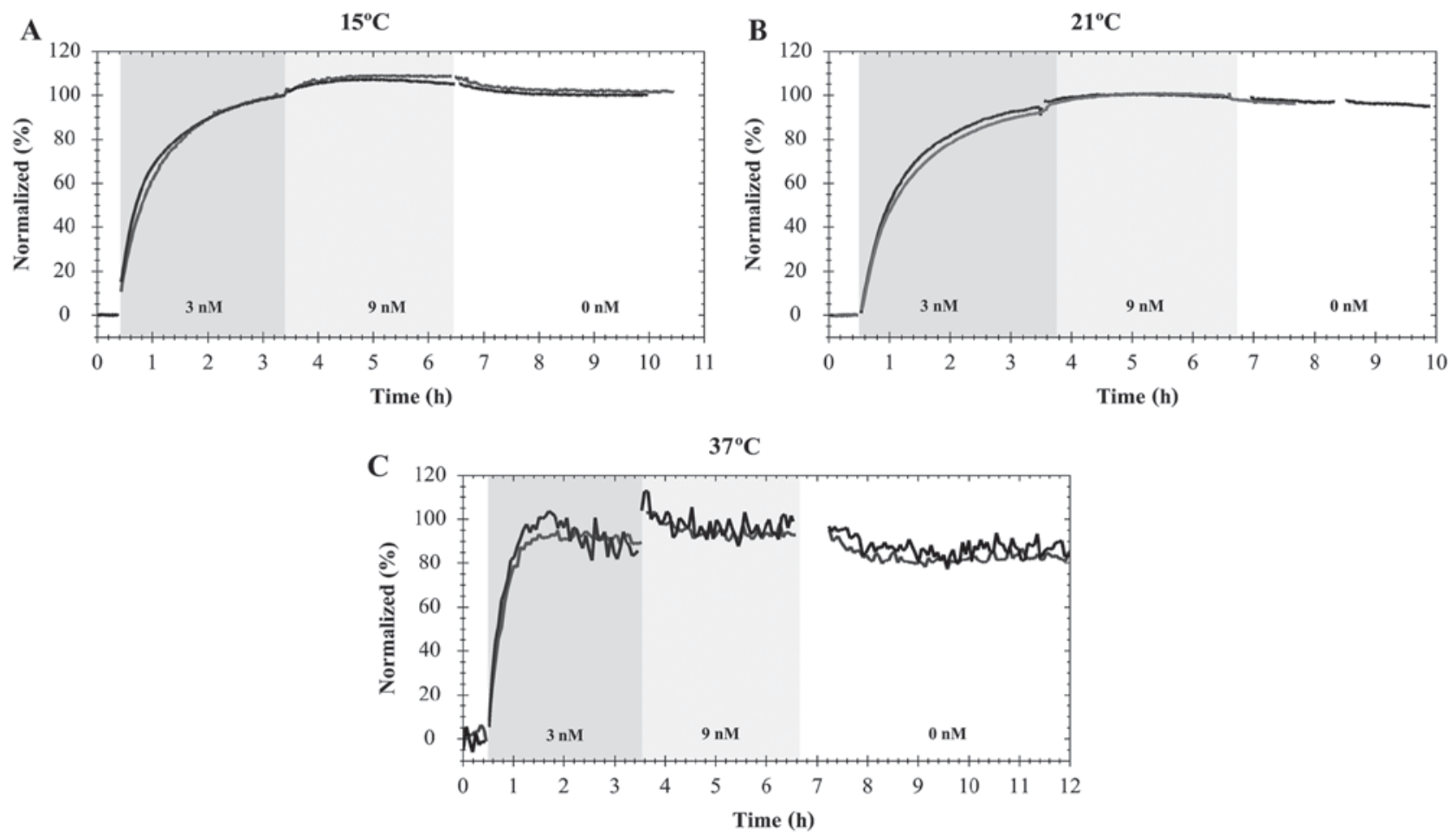

Figure 3. A431 cells were incubated with fluorescein isothiocyanate-cetuximab ( 3 and $9 \mathrm{nM}$ added step-wise; incubation time, $3 \mathrm{~h}$ per concentration) followed by the dissociation phase. Measurements were conducted at (A) $15^{\circ} \mathrm{C}(\mathrm{n}=2),(\mathrm{B}) 21^{\circ} \mathrm{C}(\mathrm{n}=2)$ and $(\mathrm{C}) 37^{\circ} \mathrm{C}(\mathrm{n}=2)$. The use of different shades of gray denotes results from individual replicates.

when the interaction required $\sim 5 \mathrm{~h}$ of incubation at $9 \mathrm{nM}$ to approach equilibrium (Fig. 3A and B). After 7-8 h, the incubation solution was replaced with fresh cell culture medium, allowing detection of the dissociation process. The estimations of the association and dissociation rate constants as the affinity at different temperatures are presented in the Table II.

\section{Discussion}

In the present study, the variation in binding behavior of clinical mAbs interacting with targets expressed on living cells under the influence of temperature was investigated. In traditional cell-based assays, the affinity measurements of protein interactions are typically performed at room temperature or at $4-8^{\circ} \mathrm{C}$, with little or no reflection of the potential impact of the temperature. It is well known that higher temperatures supply more energy, potentially increasing the reaction rate, which often leads to an accelerated interaction between ligands and targets. Therefore, temperature variation should always be accounted for to better predict the interaction behavior. The present study aimed to estimate an approximate level of influence of temperature variation on ligand-receptor interaction in living cells.

It is important to understand the possible influence of temperature on protein-protein interactions in living cells, to approach a real-life scenario, where the living cell system provides crucial information regarding the behavior of the therapeutic antibody. However, numerous challenges were identified when working with adherent living cells at different temperatures, such as viability, metabolism and cell adherence. At temperatures of $\sim 8^{\circ} \mathrm{C}$, the cells began to lose their attachment properties and, eventually, their viability (data not shown). At $37^{\circ} \mathrm{C}$, the cells were active and viable, with normal metabolism, potentially leading to the internalization and, subsequently, degradation of the antibody. On the technical side, the temperature and temperature variations influence the signal detected. The LigandTracer instrument was placed in different temperature equilibrated conditions and considerable time was required to stabilize the signal (to reduce drift) and reach the target temperature (for example $\sim 5 \mathrm{~h}$ at $37^{\circ} \mathrm{C}$ ). Therefore, it is important to monitor the temperature of the device when performing the experiment to guarantee improved data. To avoid possible error, the instrument was placed in temperature equilibrated conditions overnight prior the measurements inside of the incubator at $37^{\circ} \mathrm{C}$. A temperature change of $1-2^{\circ} \mathrm{C}$ in the instrument may destabilize the signal for a short period, making it essential to rapidly execute the manual steps of the experiment (such as the addition of ligand during which the incubator or thermobox are opened). Additionally, but not equally critical, condensation is formed on the optical detector surface leading to noise increase, which alters the aspect of the curve and increases the number of spikes in the final signal. However, an increase of noise to some extent does not necessarily disturb the measurement. Thus, taking into account the biological limitations, it is possible to measure ligand-receptor interactions at different temperatures in real-time, which provides a foundation for further investigation of thermodynamics on the interaction of mAbs in living cells.

In the current study, it was possible to observe in living cells that temperature influenced the time of incubation required to approach equilibrium. When cells were incubated at $37^{\circ} \mathrm{C}$, the interaction approached equilibrium faster than 
at either 15 or $21^{\circ} \mathrm{C}$. In contrast to manual assays, which are blind with the exception of the single measurement per well conducted following a wash, measuring in real-time reduces blind-points and enables more precise elucidation of the duration of incubation required to approach equilibrium, which may have been missed using end-point assays. Furthermore, the increase of the association rate with temperature increase, from 15 to $37^{\circ} \mathrm{C}$ was observed during the antibody interactions that were investigated. The differences in the $\mathrm{k}_{\mathrm{a}}$ at $37^{\circ} \mathrm{C}$ were three- to five-fold higher than at either 21 or $15^{\circ} \mathrm{C}$. However, these differences were not as apparent from 15 to $21^{\circ} \mathrm{C}$. The differences between 37 and $21^{\circ} \mathrm{C}$ are explained by the temperature increase and the fact that when cells are incubated with optimal temperature for normal metabolic activity, they are able to promote the interaction between the antibody and the receptors. Conversely, it was not possible to precisely evaluate the off-rate $\mathrm{k}_{\mathrm{d}}$ for pertuzumab, as the dissociation process was so slow that obtaining consistent data was not possible using a standard real-time experiment. This demonstrates that the regular assay design was not good enough for characterizing the pertuzumab-HER2 interaction.

A modified assay design was proposed and implemented for pertuzumab. The standard experiment was replaced with two separate experiments. Initially, the association process was evaluated by incubating cells with two different concentrations that were selected to obtain a clear estimation on curvature. Subsequently, in a second experiment, the HER2 system was saturated with an abundance of Texas Red-pertuzumab aiming to achieve greater sensitivity of the signal and a longer measurement duration of the dissociation process. It was possible to evaluate the two sets of experiments in parallel using TraceDrawer software, where certain variables were estimated independently (such as Bmax, associated with cell number and, thus, differs between measurements) and certain variables were estimated globally (such as the interaction parameters $\mathrm{k}_{\mathrm{a}}, \mathrm{k}_{\mathrm{d}}$ and $\mathrm{K}_{\mathrm{D}}$ ). The modified assay design enabled the estimation of the affinity and kinetics in situations where the regular assay design was insufficient for evaluating the interaction with precision.

However, accurate calculation of the dissociation rate of Texas Red-pertuzumab for $15^{\circ} \mathrm{C}$ and $21^{\circ} \mathrm{C}$ was not performed, as pertuzumab in conjugation with Texas Red has a particularly slow dissociation process. Fluorescent labels alter the normal function of the target protein and Texas Red has previously been demonstrated to slow down the dissociation process in a study where Texas Red was compared against other conjugates (22). In the same study, the values obtained for cetuximab, at room temperature with other conjugates, were similar to the values obtained in the present study with FITC-cetuximab at $21^{\circ} \mathrm{C}$.

The smaller temperature variations observed in the current study, on on-rate $\left(\mathrm{k}_{\mathrm{a}}\right)$ and off-rate $\left(\mathrm{k}_{\mathrm{d}}\right)$, result in larger equilibrium coefficient $\left(\mathrm{k}_{\mathrm{a}} / \mathrm{k}_{\mathrm{d}}\right)$ variations, and may be an interesting starting point for a more detailed calculation of the thermodynamic coefficients to provide a more complete mechanistic understanding of the biologics involved for clinical antibodies in humans. A deeper thermodynamic interpretation of the interactions requires numerous additional temperatures under steady state thermostable conditions and is beyond the scope of this particular study. The aim of the present study was to investigate the impact of temperature for the purpose of properly designing the assay. However, a study that performs a deeper thermodynamic interpretation of the interactions in living systems is planned for the future, as it may reveal interesting mechanistic details, as well as provide a more complete census and understanding of the biology in the interactions. In an earlier such investigation, the thermodynamic functions $\left(\Delta \mathrm{G}^{\circ}, \Delta \mathrm{H}^{\circ}\right.$ and $\left.\Delta \mathrm{S}^{\circ}\right)$ were derived at each site for the interaction between the optical isomers ( $\mathrm{R}$ and $\mathrm{S}$ ) of the $\beta$-blocker, propranolol and the protein, cellobiohydrolase Cel7A (27) revealing there are at least two defined type of interactions; one interaction where $\mathrm{R}$ and $\mathrm{S}$ propranolol behaved in a similar manner and one accounting for a chiral (optically active) selective interaction $(28,29)$. Similarly, detailed findings may be possible in a living cell interacting with biologics, although the experiment would be particularly complex with metabolism involved.

In conclusion, the present study observed that it was possible to measure the affinity and kinetics in living cells in real-time at different temperatures, allowing better understanding of the real behavior of protein-protein interactions in a living system and, to a certain extent, introduced the possibility of thermodynamic analysis of these interactions. Therefore, as a potential rule-of-thumb, when measuring interaction data acquired at different temperatures, the kinetics may increase (or decrease) by less than 10 -fold when comparing the physiological temperature of $37^{\circ} \mathrm{C}$ with room temperature $\left(20-25^{\circ} \mathrm{C}\right)$. The incubation time required to reach equilibrium also varies by, approximately, up to a factor 10 , which has a direct impact on the design and analysis of traditional end-point assays.

\section{Acknowledgements}

The authors would like to thank to Marika Nestor and Hanna Björkelund for their assistance with the manuscript. The study received funding from the European Union's Framework Programme for Research and Innovation Horizon 2020 (grant no. 2014-2020) under the Marie Skłodowska Curie Grant (agreement no. 675555; Accelerated Early staGe drug dIScovery). Further support was provided by Rector's Mobility Fund of Charles University 2016 and by Charles University (grant no. PRVOUK P40), and the Swedish Knowledge Foundation in a KK HÖG 15 project (grant no. 20150233).

\section{References}

1. Liu JKH: The history of monoclonal antibody developmentProgress, remaining challenges and future innovations. Ann Med Surg (Lond) 3: 113-116, 2014.

2. Martinelli E, De Palma R, Orditura M, De Vita F and Ciardiello F: Anti-epidermal growth factor receptor monoclonal antibodies in cancer therapy. Clin Exp Immunol 158: 1-9, 2009.

3. Olsson AK, Dimberg A, Kreuger J and Claesson-Welsh L: VEGF receptor signalling - in control of vascular function. Nat Rev Mol Cell Biol 7: 359-371, 2006.

4. Niu G and Chen X: Vascular endothelial growth factor as an anti-angiogenic target for cancer therapy. Curr Drug Targets 11: 1000-1017, 2010.

5. Bennouna J, Sastre J, Arnold D, Österlund P, Greil R, Van Cutsem E, von Moos R, Viéitez JM, Bouché O, Borg C, et al: ML18147 Study investigators: Continuation of bevacizumab after first progression in metastatic colorectal cancer (ML18147): A randomised phase 3 trial. Lancet Oncol 14: 29-37, 2013. 
6. Li S, Schmitz KR, Jeffrey PD, Wiltzius JJW, Kussie P and Ferguson KM: Structural basis for inhibition of the epidermal growth factor receptor by cetuximab. Cancer Cell 7: 301-311, 2005

7. van Dongen GA, Visser GWM, Lub-de Hooge MN, de Vries EG and Perk LR: Immuno-PET: A navigator in monoclonal antibody development and applications. Oncologist 12: 1379-1389, 2007.

8. Arruebo M, Valladares $M$ and González-Fernández Á: Antibody-conjugated nanoparticles for biomedical applications. J Nanomater 2009, 2009.

9. Andersson K: Bringing time into molecular and cellular biology. J Anal Oncol 2: 65-68, 2013.

10. Kastritis PL and Bonvin AMJJ: On the binding affinity of macromolecular interactions: Daring to ask why proteins interact. J R Soc Interface 10: 20120835, 2013.

11. Renaud JP, Chung CW, Danielson UH, Egner U, Hennig M, Hubbard RE and Nar H: Biophysics in drug discovery: Impact, challenges and opportunities. Nat Rev Drug Discov 15: 679-698, 2016.

12. Björke $\mathrm{H}$ and Andersson $\mathrm{K}$ : Measuring the affinity of a radioligand with its receptor using a rotating cell dish with in situ reference area. Appl Radiat Isot 64: 32-37, 2006.

13. Stenberg J, Spiegelberg D, Karlsson H and Nestor M: Choice of labeling and cell line influences interactions between the Fab fragment AbD15179 and its target antigen CD44v6. Nucl Med Biol 41: 140-147, 2014.

14. Spiegelberg D, Stenberg J, Haylock AK and Nestor M: A real-time in vitro assay as a potential predictor of in vivo tumor imaging properties. Nucl Med Biol 43: 12-18, 2016.

15. Nath N, Godat B,Zimprich C, Dwight SJ, Corona C, McDougall M and Urh M: Homogeneous plate based antibody internalization assay using $\mathrm{pH}$ sensor fluorescent dye. J Immunol Methods 431: $11-21,2016$.

16. Perera RM, Zoncu R, Johns TG, Pypaert M, Lee FT, Mellman I, Old LJ, Toomre DK and Scott AM: Internalization, intracellular trafficking, and biodistribution of monoclonal antibody 806: A novel anti-epidermal growth factor receptor antibody. Neoplasia 9: 1099-1110, 2007.

17. Winquist J, Geschwindner S, Xue Y, Gustavsson L, Musil D, Deinum J and Danielson UH: Identification of structural-kinetic and structural-thermodynamic relationships for thrombin inhibitors. Biochemistry 52: 613-626, 2013.

18. Shuman CF, Hämäläinen MD and Danielson UH: Kinetic and thermodynamic characterization of HIV-1 protease inhibitors. J Mol Recognit 17: 106-119, 2004.
19. Geitmann M and Danielson UH: Additional level of information about complex interaction between non-nucleoside inhibitor and HIV-1 reverse transcriptase using biosensor-based thermodynamic analysis. Bioorg Med Chem 15: 7344-7354, 2007.

20. ReverberiR and Reverberi L: Factors affecting the antigen-antibody reaction. Blood Transfus 5: 227-240, 2007.

21. Björkelund H, Gedda L and Andersson K: Comparing the epidermal growth factor interaction with four different cell lines: Intriguing effects imply strong dependency of cellular context. PLoS One 6: e16536, 2011.

22. Bondza S, Stenberg J, Nestor M, Andersson K and Björkelund $\mathrm{H}$ : Conjugation effects on antibody-drug conjugates: Evaluation of interaction kinetics in real time on living cells. Mol Pharm 11: 4154-4163, 2014.

23. Gedda L, Björkelund $\mathrm{H}$ and Andersson K: Real-time immunohistochemistry analysis of embedded tissue. Appl Radiat Isot 68 : 2372-2376, 2010.

24. Ekerljung L, Wållberg H, Sohrabian A, Andersson K, Friedman M, Frejd FY, Ståhl S and Gedda L: Generation and evaluation of bispecific affibody molecules for simultaneous targeting of EGFR and HER2. Bioconjug Chem 23: 1802-1811, 2012.

25. Pa $a_{s}$ zik R, Andersson R, Kępiński L, Nedelec J-M, Kessler VG and Seisenbaeva GA: Surface functionalization of the metal oxide nanoparticles with biologically active molecules containing phosphonate moieties. Case study of BaTiO 3. J Phys Chem C 115: 9850-9860, 2011.

26. Barta P, Malmberg J, Melicharova L, Strandgård J, Orlova A, Tolmachev V, Laznicek M and Andersson K: Protein interactions with HER-family receptors can have different characteristics depending on the hosting cell line. Int J Oncol 40: 1677-1682, 2012.

27. Fornstedt T: Characterization of adsorption processes in analytical liquid-solid chromatography. J Chromatogr A 1217: 792-812, 2010.

28. Ståhlberg J, Henriksson H, Divne C, Isaksson R, Pettersson G, Johansson G and Jones TA: Structural basis for enantiomer binding and separation of a common $\beta$-blocker: Crystal structure of cellobiohydrolase Cel7A with bound (S)-propranolol at $1.9 \mathrm{~A}$ resolution. J Mol Biol 305: 79-93, 2001.

29. Fornstedt T and Guiochon G: Nonlinear effects in LC and Chiral LC. Anal Chem 73: 608A-617A, 2001 